\title{
INFLUÊNCIA DA MICROESTRUTURA NA VELOCIDADE DE ONDAS ULTRASSÔNICAS EM AÇOS C-Mn*
}

Bruna Fernandes Rivelli ${ }^{1}$ Ana Cláudia Azevedo Dias ${ }^{1}$ Elexander da Costa Junior ${ }^{1}$ Fagner de Paula Marques ${ }^{2}$ Carlos Roberto Ferreira ${ }^{3}$

Vicente Braz Trindade ${ }^{4}$

\section{Resumo}

A fabricação de componentes de aços para a indústria mecânica, como por exemplo, indústria petrolífera, requer um rigoroso controle de qualidade através de técnicas de ensaios destrutivos e não destrutivos com o objetivo de caracterizar os aços quanto suas microestrutura/propriedades mecânicas e sua integridade estrutural e dimensional. Neste estudo foram utilizados dois aços C-Mn empregados na fabricação de tubos para extração e condução de óleo e gás. Foi realizada análise microestrutural utilizando microscopia eletrônica de varredura (MEV). Dureza foi realizada em amostras de diferentes microestruturas, tais como estado como temperado e como temperado e revenido em diferentes temperaturas. Medidas de velocidades ultrassônicas usando ondas longitudinais foram realizadas em todas as amostras. Observou-se uma significativa influência da microestrutura na velocidade de ondas ultrassônicas, principalmente para o aço que contem médio teor de carbono, enquanto que para o aço baixo carbono, a variação da velocidade ultrassônica foi insignificante para os diferentes tratamentos térmicos. A velocidade de onda ultrassônica na martensita foi inferior quando comparada com a martensita revenida. De maneira análoga, quanto maior a temperatura de revenimento, menor a dureza e maior a velocidade ultrassônica.

Palavras-chave: Velocidade ultrassônica; Aço C-Mn; Microestrutura; Dureza.

\section{INFLUENCE OF MICROSTRUCTURE OF C-Mn STEELS ON THE ULTRASONIC} VELOCITY

\section{Abstract}

The manufacturing of components for mechanical industries, e.g. oil\&gas industry requires a stringent quality control by means of destructive and non-destructive tests aiming the evaluation of the microstructure/mechanical properties and the integrity/dimensional characteristics. In this study it was investigated two C-Mn steels commonly used in the oil\&gas industry. It was performed microstructural analysis using scanning electron microscopy (MEV). Hardness measurements were done in different conditions: as-quenched and after two different tempering temperatures. Measurements of the ultrasonic velocities using longitudinal waves were performed in all samples. It was observed a considerable influence of the microstructure on the ultrasonic velocity, mainly for the steel containing medium carbon. For the steel with low carbon content, the ultrasonic velocity variation was practically not relevant for most industrial applications. The ultrasonic velocity in the martensite was the lowest when compared with the tempered martensite. Similar situation, the higher the tempering temperature, the hardness is lower and the more ultrasonic velocity.

Keywords: Ultrasonic speed; Steel C-Mn; Microstructures; Hardness.

1 Estudante de Engenharia Metalúrgica, Instituto Federal de Minas Gerais, Ouro Branco, Minas Gerais, Brasil.

2 Estudante de Engenharia de Produção, Faculdade Santa Rita, Conselheiro Lafaiete, Minas Gerais, Brasil.

3 Engenharia Metalúrgica, DSc, Professor, Departamento de Engenharia Metalúrgica, Instituto Federal de Minas Gerais, Ouro Branco, MG, Brasil.

4 Engenharia Metalúrgica, PhD, Professor, Departamento de Metalurgia e Materiais, Universidade Federal de Ouro Preto, Ouro Preto, MG, Brasil. 


\section{INTRODUÇÃO}

A caracterização de aços é realizada basicamente em condições de laboratório através de ensaios destrutivos, como por exemplo, microestrutura usando microscopia e/ou comportamento mecânico através de ensaios de dureza, tração e impacto. Apesar do notório reconhecimento destes ensaios em condições de laboratório, é crescente a necessidade de desenvolver metodologias para avaliação do comportamento dos materiais através de ensaios não destrutivos. O uso desta metodologia proporcionará enorme impacto no custo de produção, controle de processo na fabricação de aços e controle da qualidade de equipamentos em operação.

A relação entre microestrutura e propriedades mecânicas de aços tem sido estudada ao longo de séculos com contínuo sucesso [1-4], apesar de ainda haver muito trabalho a ser realizado.

Existem várias pesquisas [5-7] no sentido de relacionar aspectos microestruturais com propriedades físicas dos materiais, como velocidade ultrassônica, campo de fuga magnético, correntes parasitas, dentre outras. No entanto, observa-se que não existem relações claras, que podem ser extrapoladas para todos os aços, entre as propriedades físicas acima mencionadas e a microestrutura dos aços. $\mathrm{Na}$ opinião dos autores deste artigo, estas correlações devem ser realizadas com grande cuidado e ser consideradas condições bem específicas em termos de composição química do aço e tipo de tratamento térmico.

O objetivo deste estudo é medir a velocidade ultrassônica de dois aços C-Mn contendo diferentes teores de carbono: baixo carbono $(0,06-0,10 \%$ em massa) e médio carbono $(0,25-0,32 \%$ em massa), submetidos aos tratamentos térmicos de têmpera em água e revenimento em diferentes temperaturas. Serão realizadas correlações entre a microestrutura e a velocidade ultrassônica, bem como entre a velocidade ultrassônica e a dureza dos aços em diferentes condições de tratamentos térmicos.

\section{MATERIAIS E MÉTODOS}

Para identificação da velocidade de propagação das ondas ultrassônicas foram utilizadas amostras de dois aços C-Mn com diferentes teores de carbono: médio e baixo teores. Os aços foram lingotados em forma de barras redondas em uma máquina de lingotamento contínuo. Os tubos foram laminados a quente nas dimensões $244 \mathrm{~mm}$ de diâmetro externo e $15 \mathrm{~mm}$ de espessura de parede. Após laminação, os tubos foram tratados termicamente. O tratamento térmico utilizado foi têmpera em água e revenimento nas temperaturas de $640^{\circ} \mathrm{C}$ e $670^{\circ} \mathrm{C}$. As composições químicas especificadas dos dois aços estão apresentadas na Tabela 1.

Tabela 1. Composição química especificada dos aços de acordo com as normas API 5CT e API 5L.

\begin{tabular}{|c|c|c|c|c|c|c|c|}
\cline { 2 - 8 } \multicolumn{1}{c|}{} & $\mathbf{C}$ & $\mathbf{M n}$ & $\mathbf{M o}$ & $\mathbf{T i}$ & $\mathbf{B}$ & $\mathbf{C r}$ & $\mathbf{N b}+\mathbf{V}$ \\
\hline Aço 1 & $0,25-0,32$ & $1,2-1.9$ & $0,5-1,2$ & $0,015-0,030$ & $0,0010-0,0018$ & $0,5-1,2$ & --- \\
\hline Aço 2 & $0,06-0,10$ & $0,7-1,4$ & $<0,10$ & $<0,02$ & $<0,0007$ & $<0,012$ & $<0,07$ \\
\hline
\end{tabular}


Os corpos de prova para medição da velocidade ultrassônica foram retirados das amostras nos estados como temperado e como temperado e revenido, conforme Figura 1. Os corpos de prova foram retificados com o objetivo de garantir um excelente controle de sua espessura com variação máxima de $\pm 0,005 \mathrm{~mm}$.

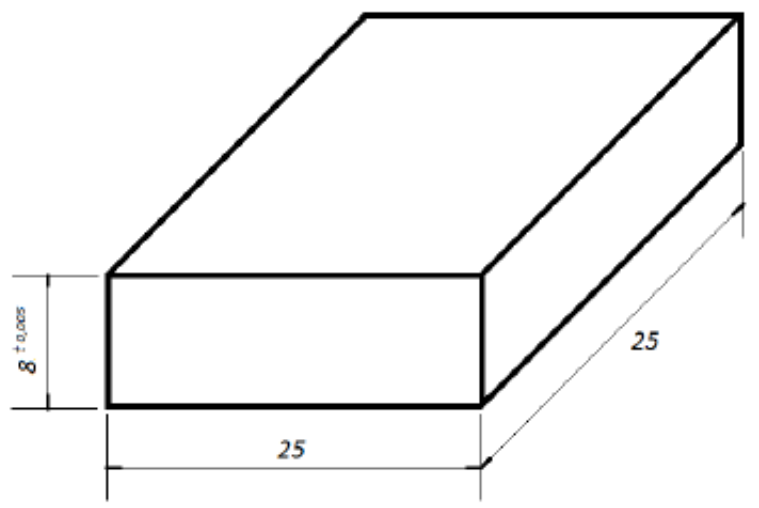

Figura 1. Dimensões dos corpos de prova em mm para medidas da velocidade ultrassônica. A direção de propagação da onda é no sentido da espessura do corpo de prova.

Os corpos de prova para análise metalográfica foram cortados ao lado dos corpos de prova para medição da velocidade ultrassônica. A preparação metalográfica procedeu-se com lixamento utilizando lixas de SiC com granulometrias de \#100 a \#1500, seguida de polimento com pasta de diamante com granulometria de 0,5 e 1,0 $\mu \mathrm{m}$. Foi realizado ataque com Nital $2 \%$ para análise no microscópio ótico e microscópio eletrônico de varredura (MEV).

Ensaios de dureza Vickers com carga de $10 \mathrm{Kgf}$ (HV10) foram realizados nos corpos de prova utilizados na análise metalográfica.

Ensaio Jominy com corpos de prova reduzidos de acordo com a norma NBR 6339 foram retirados dos tubos no estado laminado. A austenitização foi realizada a $920^{\circ} \mathrm{C}$ durante $10 \mathrm{~min}$.

A realização das medições foi feita através da técnica pulso eco utilizando um aparelho de ultrassom do tipo DM5E calibrado e com comprovação metrológica, um transdutor duplo cristal de efeito piezoelétrico com frequência de $5 \mathrm{MHz}$, um cabo coaxial, um bloco padrão escalonado com um degrau de $8 \mathrm{~mm}$ e, como acoplante, foi usada uma mistura de carboximetilcelulose com água e álcool etílico.

\section{RESULTADOS E DISCUSSÃO}

Os dois aços são utilizados na indústria de óleo e gás com diferentes funções. O aço contendo médio carbono é utilizado para recobrimento de poços de extração de petróleo, não requerendo nenhuma operação de soldagem. O elevado teor de carbono equivalente é extremamente benéfico para a temperabilidade deste aço; além disto, a adição de Ti-B contribui para a melhoria da temperabilidade. A Figura 2 mostra o resultado do ensaio Jominy dos dois aços. Pode-se observar a baixa temperabilidade do aço 2 que contém baixo teor de $\mathrm{C}$. $\mathrm{O}$ aço 2 é aplicado na condução de óleo e gás e é submetido à operação de soldagem. A formação de martensita no aço 1 atinge uma profundidade em torno de $20 \mathrm{~mm}$, enquanto o aço 2 forma martensita em uma profundidade de aproximadamente $2 \mathrm{~mm}$. 


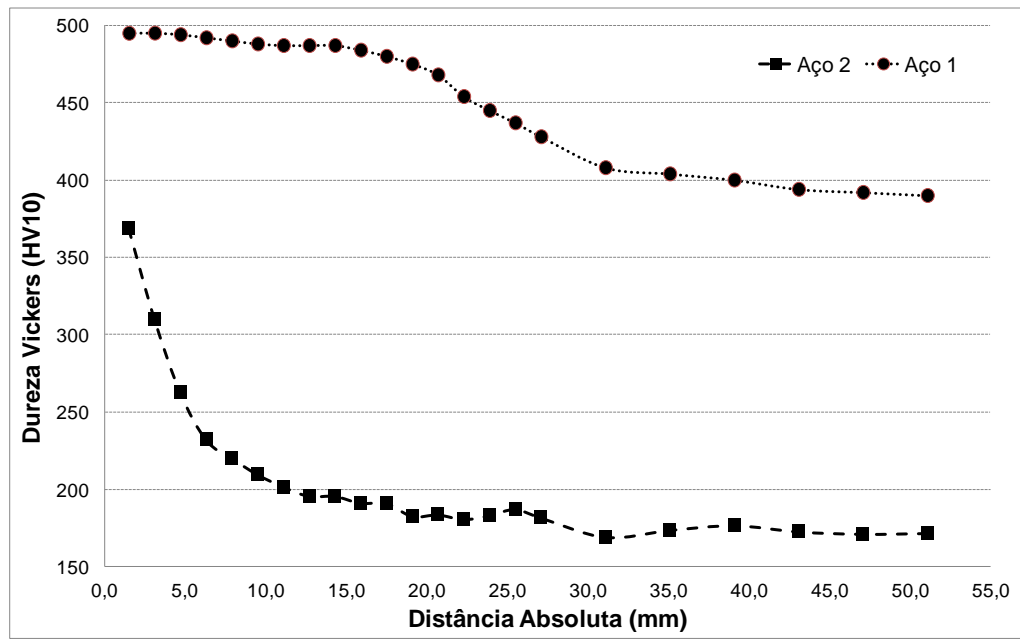

Figura 2. Resultado do ensaio Jominy para os dois aços.

Após têmpera em tanque de água em escala industrial, pode-se observar a presença de mais de $95 \%$ de formação de martensita no aço 1. A Figura 3a mostra a microestrutura do aço 1 no estado como temperado. A microestrutura do aço 2, como temperado nas mesmas condições do aço $1 \mathrm{em}$ escala industrial, é basicamente bainita com presença de martensita próxima à superfície, devido à elevada taxa de resfriamento, conforme Figura 3b.

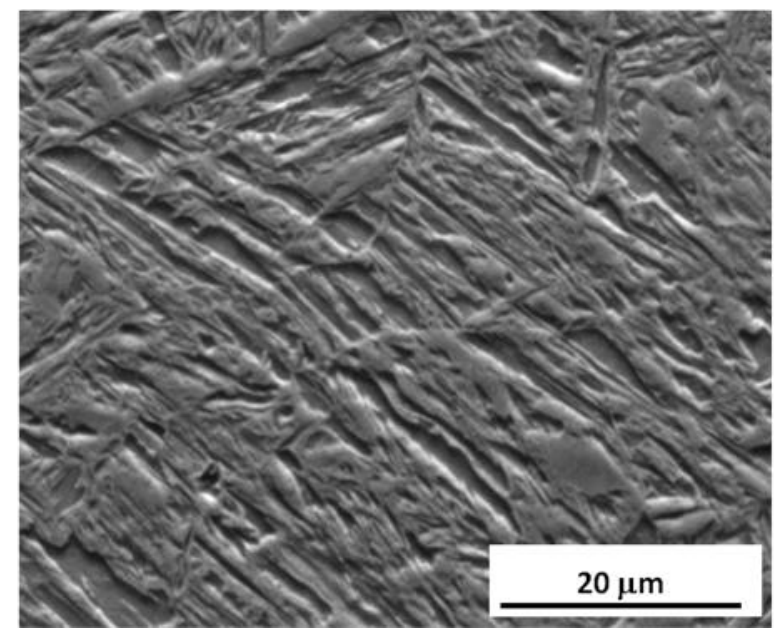

(a)

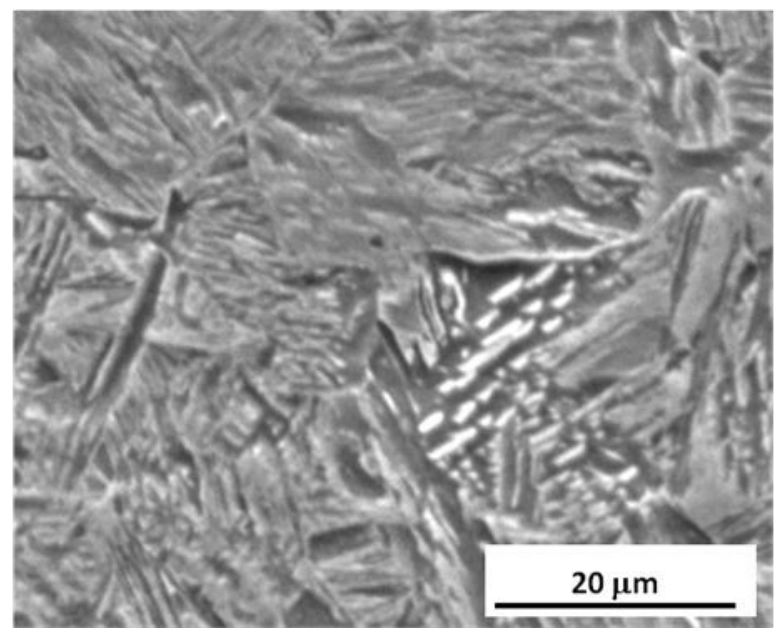

(b)

Figura 3. Microestrutura dos aços no estado como temperado em escala industrial: (a) aço 1 e (b) aço 2.

No aço 1, na condição de têmpera e revenimento em diferentes temperaturas, forma-se a martensita revenida caracterizada por diferentes quantidades de precipitados de carbonetos $\left(\mathrm{Fe}_{3} \mathrm{C}\right)$. Consequentemente, obtém-se diferentes propriedades mecânicas, como por exemplo, limite de escoamento, limite de resistência, impacto Charpy e dureza. A Figura 4 mostra a microestrutura dos aços 1 e 2 após revenimento. Pode-se observar que o aço 2 apresenta uma microestrutura mais fina em forma de ripas de martensita, enquanto que para o aço 2 forma-se uma microestrutura mais grosseira, mais próxima de bainita. 


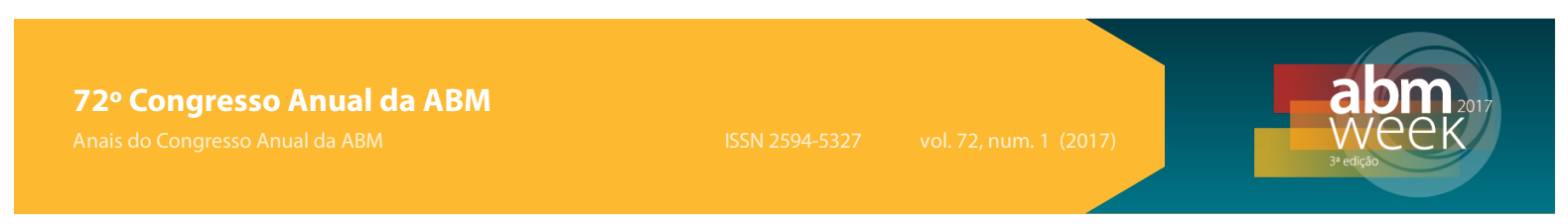

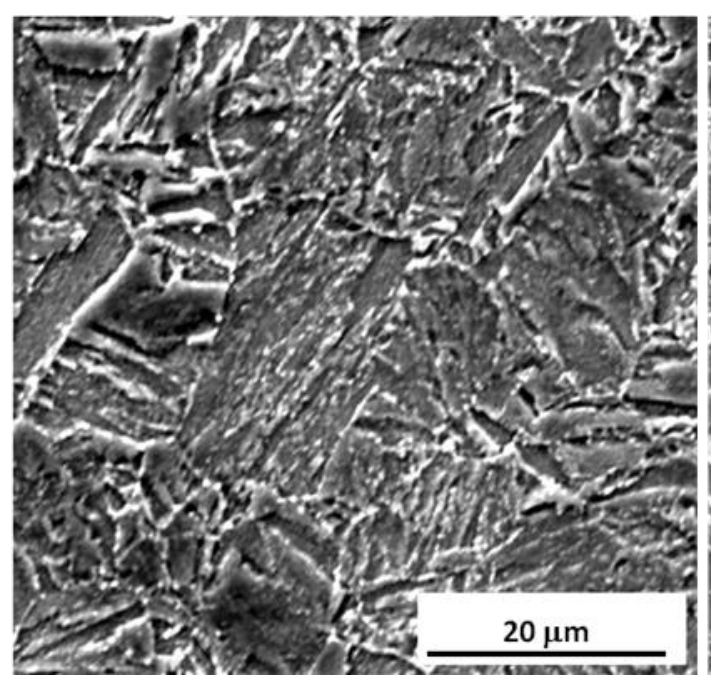

(a)

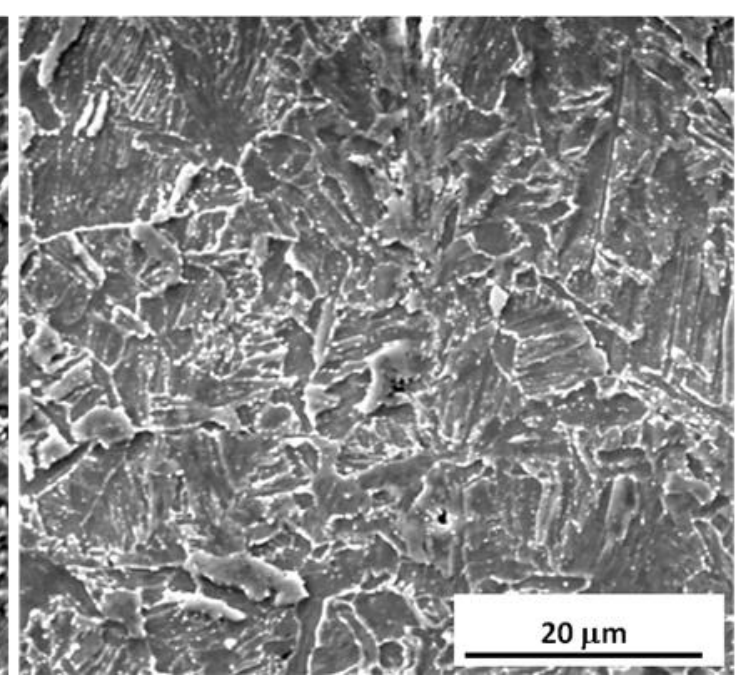

(b)

Figura 4. Microestrutura após revenimento: (a) aço 1 revenido a $650^{\circ} \mathrm{C} / 30 \mathrm{~min}$. e (b) aço 2 revenido a $650{ }^{\circ} \mathrm{C} / 30 \mathrm{~min}$. As partículas de cor branca são carbonetos do tipo $\mathrm{Fe}_{3} \mathrm{C}$, precipitados durante $\mathrm{o}$ revenimento.

Medições da velocidade ultrassônica foram realizadas em corpos de prova com diferentes microestruturas e com espessura conhecida. Pode-se observar na Figura 5 que a velocidade ultrassônica do aço 1 no estado como temperado é mais baixa e aumenta com o aumento da temperatura de revenimento. Uma possível interpretação física deste comportamento pode ser devido ao fato de que a martensita é uma solução supersaturada de carbono e, devido a esta supersaturação, os átomos de ferro tem pouca "liberdade" para vibrar e, consequentemente, propagar a onda ultrassônica. À medida que se realiza revenimento, parte do carbono difunde para fora da martensita e precipita em forma de cementita, dando mais "liberdade" aos átomos de ferro para vibrar e aumentar a velocidade ultrassônica. Quanto mais se aumentar a temperatura de revenimento, mais carbono difundirá para fora da martensita e, portanto, maior será a velocidade ultrassônica. Para o aço 2, se observa um comportamento bastante diferente daquele descrito para o aço 1: como temperado, a velocidade ultrassônica do aço 2 é muito superior à velocidade ultrassônica do aço 1. Este comportamento pode ser explicado pelo fato de que o aço 2 possui baixo carbono e, durante a têmpera, forma-se pouca martensita, ou seja, praticamente bainita. Com o revenimento, a microestrutura do aço 2 não muda muito e, assim, a velocidade ultrassônica varia muito pouco quando comparada com o que acontece para o aço 1. 


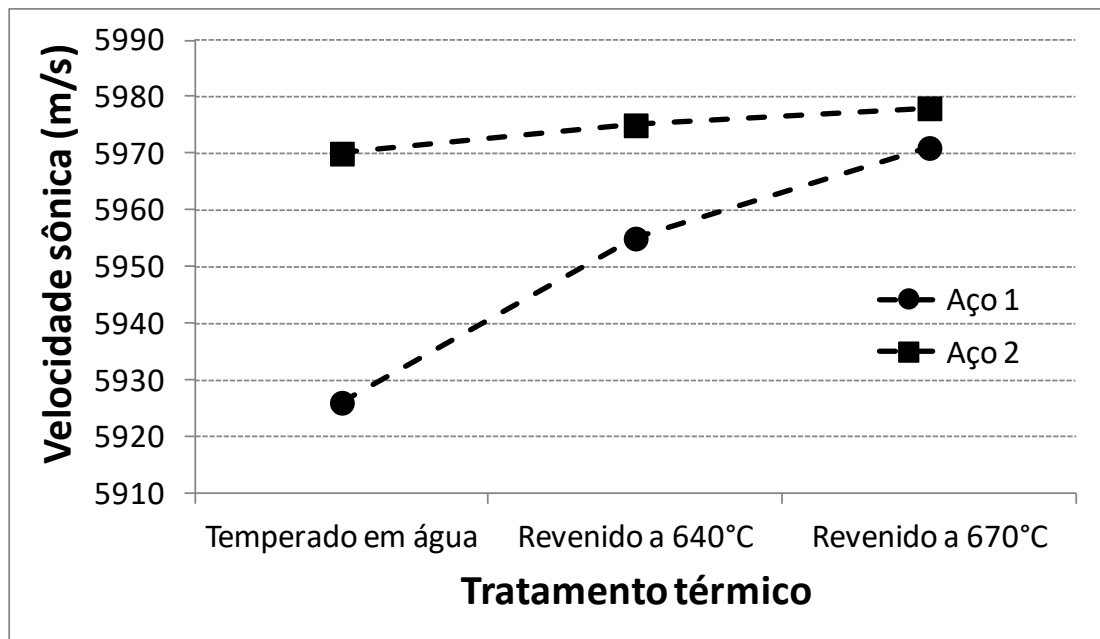

Figura 5. Velocidade ultrassônica em função da microestrutura dos aços 1 e 2.

A Figura 6 mostra a relação dureza versus velocidade ultrassônica para os dois aços estudados. Como se pode observar, para o aço 1, à medida que a dureza diminui, a velocidade ultrassônica aumenta como consequência do revenimento da martensita. Já para o aço 2, a diminuição da dureza com o revenimento é menos pronunciada quando comparada com o aço 1 e, dessa forma, o revenimento do aço 2 é menos sensível à variação da velocidade ultrassônica com o revenimento, ou seja, com a variação de dureza.

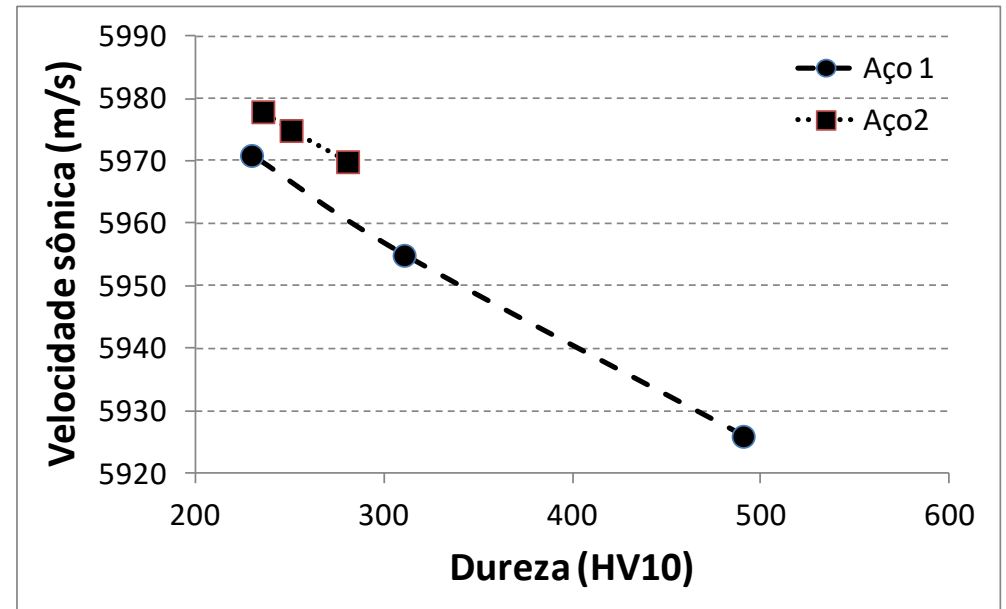

Figura 6. Relação entre a velocidade ultrassônica e dureza dos aços 1 e 2 em diferentes condições de tratamentos térmicos.

\section{CONCLUSÕES}

A avaliação de ensaio Jominy com os dois aços, baixo e médio carbono, usando corpos de prova reduzidos mostrou claramente a grande diferença no comportamento destes dois aços quanto à temperabilidade.

A têmpera em escala industrial também mostrou comportamento bastante diferente dos dois aços. O aço 1, com médio carbono, formou mais de $95 \%$ de martensita, enquanto 0 aço 2, baixo carbono, formou martensita apenas na superfície (aproximadamente $2 \mathrm{~mm}$ de espessura) e, o restante da seção, constituiu-se de bainita. 
Medidas de velocidade ultrassônica nos dois aços, com diferentes microestruturas, revelou claramente que para o aço 1 a microestrutura influenciou mais na velocidade ultrassônica do que para o aço 2. Este fenômeno pode ser explicado pelo fato do aço formar majoritariamente martensita durante têmpera, que, devido à supersaturação da martensita em carbono, inibe a vibração dos átomos de ferro e, portanto, reduz a velocidade ultrassônica na martensita. À medida que se eleva a temperatura de revenimento propicia-se a saída de átomos de carbono da martensita e, como consequência, dá-se liberdade à vibração dos átomos de ferro e aumento da velocidade ultrassônica através da martensita revenida. Para o aço 2 , com baixo teor de carbono, a velocidade ultrassônica no estado temperado é muito superior àquela observada para o aço 1; isto se deve ao fato de que, no aço 2 , a microestrutura no estado como temperado é basicamente bainita e, deste modo, os átomos de ferro tem menos restrição à vibração que em uma microestrutura martensítica. À medida que se revine a bainita, ocorre um ligeiro aumento da velocidade ultrassônica, similarmente ao observado para o aço 1.

De maneira geral, pode-se dizer que a variação da velocidade ultrassônica em um aço médio carbono com diferentes microestruturas pode ser de relevância para o controle de qualidade. Enquanto que a variação da velocidade ultrassônica em um aço baixo carbono pode ser negligenciada em diversas aplicações industriais.

\section{REFERÊNCIAS}

1 Badeshia, HKDH, Honeycombe, R. Steels: Microstructure and Properties, $3^{a}$ edição, Elsevier, 2006.

2 Silva, ALC, MEI, PR. Aços e Ligas Especiais, $2^{a}$ edição, Bluecher, 2006.

3 Calister, WD. Ciência dos Materiais, uma Introdução, 7ª edição, LTC, 2007.

4 Colpaert, H. Metalografia dos Produtos Siderúrgicos Comuns, 4a edição, Edgar Bluecher, 2008.

5 Kumar, A, Choudhary, BK, Laha, K, Rao, KBS. Characterisation of Microstructure in 9\% Chromium Ferritic-Steels Using Ultrasonic Measurement, Trans. Indian Inst. Met. 56 (5), 2003: pp. 483-497.

6 Yasunaga, M, Funatusu, Y, Kojima, S, Otsuka, K, Suzuki, T. Ultrasonic Velocity near the Martensitic Transformation Temperature, Jounal de Physique, Colloque 4, Supplément au n12, Tome 43, 1982: pp 603-608.

7 Rayes, MME, Danaf, EAE, Almajid, AA. Ultrasonic Characterization of Heat-Treatment Effects on SAE-1040 and -4340 Steels, Journal of Materials Processing Technology, 216, 2015: pp 188-198. 